\title{
Aleksandr Georgiyevich Rozanov (On His 75th Birthday)
}

DOI: $10.1134 / \mathrm{S} 000143701101022 \mathrm{X}$

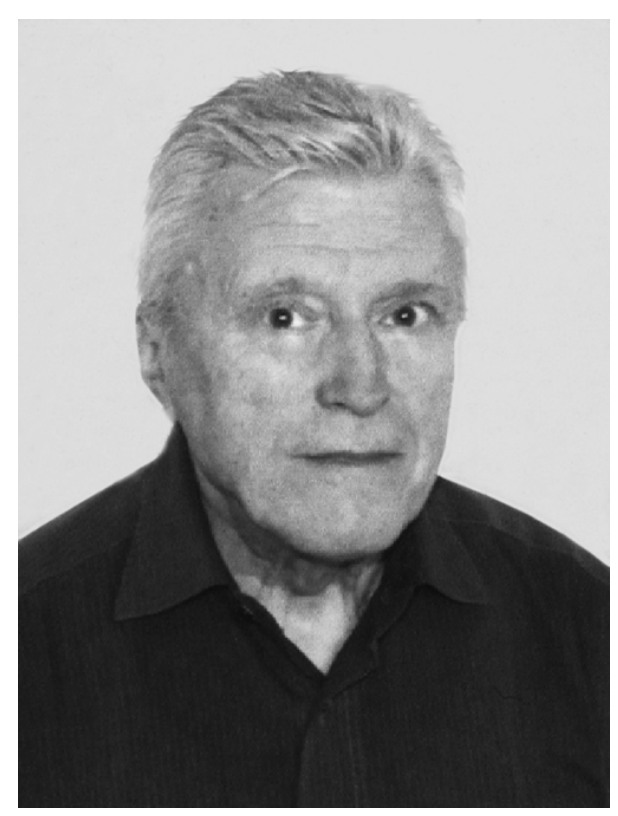

On November 30, 2010, Prominent Researcher in the Field of Marine Chemistry and Member of the Editorial Staff of the Journal Oceanology Aleksandr Georgiyevich Rozanov celebrates his 75th birthday.

All the research activity of A.G. Rozanov is associated with the Shirshov Institute of Oceanology, which he joined in 1958 after graduating from the Chemical Department of Moscow State University. A.G. Rozanov's research activity includes, among other works, the discovery of an hypoxia phenomenon in the transitional water of the Arabian Sea (in coauthorship with V.N. Ivanenkov); later, the study of hypoxia became one of the most important branches of the chemistry and ecology of the World Ocean. The works of Rozanov on oxidation-reduction processes and sulfide for- mation (in coauthorship with I.I. Volkov) brought about new ideas concerning postsediment transformations in sea bottom sediments. These works made up the basis of the chemical part of the Pacific Program of Academician Strakhov. The pioneering research of A.G. Rozanov and his colleagues into the chemistry of sulfides in the ocean within the framework of the international project Global Biogeochemical Cycle of Sulfide (1983) led to the publication of a cognominal monograph. The field of Rozanov's deepest interest within this project is the planetary processes and the budget of the sulfide cycle of the ocean.

Since the end of the 1980s, Rozanov has conducted a new line of research associated with the processes of the chemical exchange at the water-bottom boundary and has shown how important they are for the formation of the sea water and bottom sediments. The result of these studies was the publication of the monograph Chemical Exchange at the Water-Bottom Boundary in the Oceans and Seas (in coauthorship with A.V. Vershinin) in 2002. A.G. Rozanov is one of the ideologists of the creation of a bottom station for measurements of the fluxes of chemical elements through the surface of the bottom. The chemical exchange at the water-bottom boundary and its specifics in ecosystems of different latitudes with different levels of productivity are at present the priorities in A.G. Rozanov's scientific work.

Rozanov is the author of more than 160 scientific publications. He participated in many large sea expeditions of the Institute of Oceanology and some of them were headed by him. For quite a long period, Aleksandr Georgiyevich headed the Analytical Laboratory and the Laboratory of the Chemistry of the Bottom Layer at the Institute of Oceanology of the Russian Academy of Sciences. He was also an adviser for many scientific works for candidate and graduate degrees in the field of chemistry.

The editorial staff of the Oceanology journal send their greetings and best wishes for good health and success in new creative plans, achievements in research for gifted disciples and followers, and all the best of life for those with jubilees. 